\title{
WEB-BASED TRAFFIC TICKET DATA PROCESSING INFORMATION SYSTEM
}

\author{
Faikul Umam ${ }^{1}$, Rachmad Hidayat ${ }^{2}$ \\ ${ }^{1}$ Mechatronic Engineering Departement, Faculty of Engineering, University of Trunojoyo Madura Indonesia \\ ${ }^{2}$ Industrial Engineering Department, Faculty of Engineering, University of Trunojoyo Madura Indonesia \\ E-mail : ${ }^{1}$ faikul@trunojoyo.ac.id, ${ }^{2}$ rachmad.trunojoyo@gmail.com
}

\begin{abstract}
The purpose of the present study was to generate a WEB-based traffic ticket data processing information system to simplify the management of traffic offender data. This study used a structured analysis method, which is a technique to collect data and determine the facts in a systems design. A Traffic Ticket Data Processing Information System provides information concerning the amount of fines, articles violated, time and place of the trial, providing ease of information effectively and accurately. However, the characteristics of the information generated had not yet had a proper quality in terms of accuracy, completeness or timeliness of the information. As end-users, communities have not been satisfied with the information generated. The information system has not been functioning as a management information system for in the implementation stage there were still many obstacles and shortcomings so that the information generated could not be used for decision and policy making.
\end{abstract}

Keywords: traffic ticket data processing, ease of information, information timeliness, information quality

\section{INTRODUCTION}

Globalization and advances in science and technology have significant impacts on people's lives. A closer look at the impacts would indicate that a very practical and modern way of life almost occurs in all aspects of people's lives, no exception the legal aspect. The technological developments also have impacts on levels of crime and offenses committed by people. Law and society are two inseparable things since they are interrelated. Law enforcement on Road Traffic and Transportation covers the prosecution of violations and handling of Traffic Accidents. Prosecution of violations is carried out by on-road checks of motor vehicles. In the case of violations during the checks, prosecution may be taken by fast procedure and imposition of fines.

On-road checks of motor vehicles carried out by police officers and civil servant investigators LLAJ includes: (1) checks of Driving License, Certificate of Motor Vehicle Number, Certificate of Vehicle Test; (2) proof of passing compulsory vehicle test; (3) physical checks of motor vehicles; (4) load capacity and/or modes of transport; (5) Transportation Service Business License. Police officers have the authority for on-road checks of points 1 to 5 . The civil servant investigators have the authority for checks of points 2 to 5. With regard to the authority for on-road checks of motor vehicles, police officers have the full authority, including that held by the civil servant investigators.

Authority for on-road checks of motor vehicles must have relevance to the previous governmental authority. Checks of motor vehicles shall have legal certainty. It should be based on official duties in the form of an Assignment Letter issued by the supervisor of the police officers or the supervisor of the civil servant investigators. Under Law No. 22 of 2009 , traffic tickets is one form of quick examination procedure applied specifically to certain traffic violations. Actions categorized as violations are those that are visibly identified, do not need means of proof and do not need expert witnesses. Traffic ticket is a simplified police investigation report that specifies the identity of the offender, the type of offense, the location of the offense, the evidence requested, the time of trial and the data of the law enforcer along with the signature.

A ticket consists of 5 sheets of different colors. The red and blue sheets are for the offender, green for the court, white for the prosecutor and yellow for the police. The ticket serves as a summons to the District Court. It also serves as a cover note for the payment of fines to the Bank/Registrar. Another function is as a certificate of forfeiture of the seized proof (such as driver's license, vehicle registration certificate, motor vehicle). With regard to the settlement of a traffic ticket, there are two options that may be chosen by the people. One option is for those offenders who admit their guilt and are willing to pay a fine to the Bank and is represented by a designated police officer; the offenders are given a blue form. Another option is for those offenders who do not admit their guilt, those who are against the officers by refusing to sign the ticket and/or those offenders who commit offenses in the Traffic Order Zone.

In the first option, the police prosecute the offender using the blue form and suggest the offender to pay a fine to the Bank (with the maximum time limit of 5 days). After being validated by Bank's registration stamp, the police immediately restore the evidence. The traffic ticket files submitted cumulatively by the police to District Court are attended by a designated representative. In the second option, the police prosecute the offender using the red form. The day of trial must consider the provisions of the Court, which explain when and where the offender must attend the trial. If the offender is absent from the trial, the Police will make two summons and make an arrest for the third summons. Evidence shall be returned awaiting the 
completion of the trial and after the offender pay the fine to the Registrar.

To assist the police and the people with regard to improving the settlement of traffic tickets, a WEB-based traffic ticket data information system is required, which can generate traffic ticket information quickly, at any time round the clock. This information system is aimed at reducing traffic violations committed by the people as well as increasing public awareness of safe, orderly and proper driving. The purposes of the present study were to improve efficiency and effectiveness of ticketed motor vehicle data management, to assist the police in addressing and reducing traffic offenses and to improve the order in driving.

In this study, the traffic ticket data information system used a Personal Home Page (PHP): Hypertext Preprocessor programming language. The PHP Preprocessor is a programming language that runs on a web server. PHP itself was created by the programmer of Unix and Perl named Ramsus Lerdorf in 1994. At first, Ramsus was trying to create a script in his website (Zajaczek J.E.W. et. al., 2006). PHP script itself is a programming language that runs on a web server, or often called a server side. Therefore, PHP can do anything that can be done by other CGI programs, such as processing any type of data. A server side itself means that three main programs, i.e., a web server (either IIS, Apache, or other web server that supports PHP), a PHP module and a web-browser, are required to run this program (Williams H.E., \& Lane D., 2004). PHP can run on various operating systems, including Linux, Unix, Microsoft Windows, Mac OSX, RISC OS, SUN OS, and many more.

One of the considerations for choosing the PHP as the programming language of the server side is that there are many alternative operating systems and web servers that can be used. Outputs generated by PHP are not only limited to HTMLs, but also images, PDF files, as well as animated images using Libswf and Ming. Other outputs of text type may be XHTML and XML. Thus, a program with an interactive display can be created. The working system of PHP begins with a request coming from the web page by the browser. Based on the URL or address in the network the browser will find the address of the web server, identify the desired page and submit all information required by the web server (Davis M.E. and Phillips J.A., 2007).

When the page contains a PHP script, the web server will check the file type requested. If a PHP is requested, the web server will examine for a PHP script in the page. If a PHP script is not found in the page, the web server will be displayed in the browser. However, if the page contains a PHP script, the web server will continue it on the PHP module as the engine that translates and process the PHP script to be convertible to HTML codes and displayed to the user's browser (Valade J., 2007).

In building a sound and accurate application system, the system must also have a good data storage system. One good and widely used database storage system is a web-based application, such as MySQL.
MySQL is selected as the database storage since it (1) has rapid access when used; (2) is multi-platform that can run on various operating systems; (3) can accommodate up to a terabyte of data; (4) is in accordance with the PHP programming. Additionally, its free-of-charge nature in its use requires no purchase [3]. Data is an essential part of modern programming so that all programming languages provide functions to access the database. The main standard database language is Structured Query Language (SQL).SQL is standardized as a language to create a database to store information into the database and retrieve information out of it (Ullman L.E., 2003).

\section{METHODOLOGY}

This study began with conducting systems analysis and preparing a use diagram and Sequence Diagram. Furthermore, it proceeded with the design of the data base and application of traffic ticket data processing information system. With PHP and MySQL, processing and retrieval of the required traffic ticket data can be done practically [7]. Access rights in the system are divided into: (1) user, in this case all users can access the added data; (2) admin is the user who has special access rights to data management and also data manipulation (insert, update, delete);and (3) hardware required is a personal computer (PC) or a notebook.

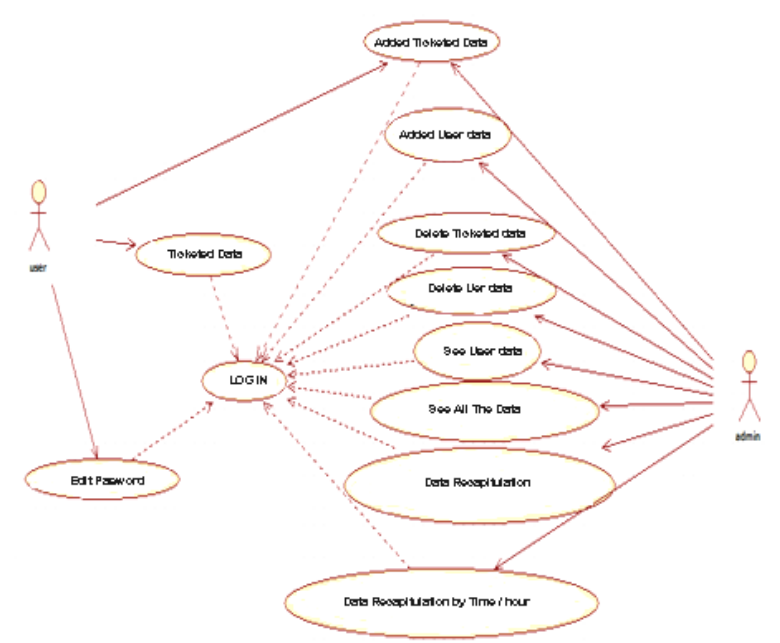

Figure-1. The Use Case Diagram

A Use Case diagram illustrates the functionality expected of a system. It represents an interaction between the actor and the system shown in Figure 1. A use case diagram presents the interaction between a use case and an actor, where the actor can be a person, equipment, or other systems that interact with the system being built. In the use case, there are actors who play roles in this application, the user and the administrator. This diagram illustrates the overall functions of the Ticketed Motor Vehicle Data Processing Information System application.

The user (in this case, or the Police District Command, locally known as the Polres) is required to login first to operate other activities, such as add data, view traffic ticket data and change password. The 
Police Provincial Command admin can add, change and delete traffic ticket data. Additionally, it can view traffic ticket data and the summary of traffic ticket data and change the password. Prior to conducting any activity, the administrator must go through the login process first.

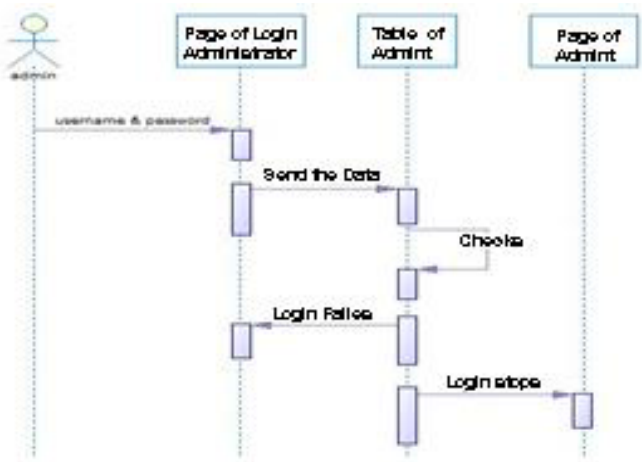

Figure-2. The SequenceDiagram of Admin Login

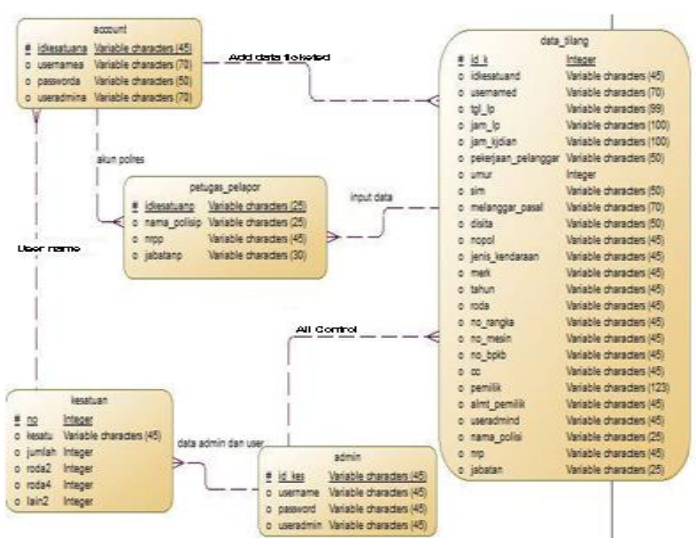

Figure-3. Conceptual Data Model

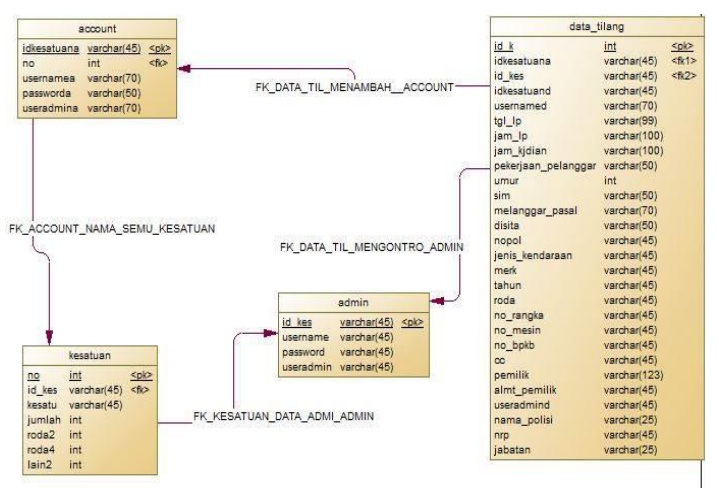

Figure-4. Physical Data Model

Inter-object interaction and communication is depicted in a Sequence Diagram shown in Figure 2. This diagram shows a series of messages exchanged by objects that perform a specific task or action. The objects are then sorted from left to right, with the actor initiating the interaction usually being placed the leftmost of the diagram.

In the design of the database, there are two kinds of model: (Figure 3) Conceptual Data Model $(\mathrm{CDM})$ is a model based on the assumption that the real world consists of a collection of basic objects called entities and relationships between these entities. The CDM is usually represented in the form of an Entity Relationship Diagram. (Figure 4) Physical Data Model (PDM) is a model which uses a number of tables to describe the data as well as the relationship between these data. Each table has a column in which each column has a unique name.

\section{RESULTS AND DISCUSSION \\ Traffic Ticket Data Processing Application}

The two early steps to run this application are to enable the server module and then open the web browser by typing the web application's address in the address bar of the web browser. The first step to enter the Traffic Ticket Data Processing application is to enter the homepage of this application. Upon selection of the login menu, the login page will come into view. When the admin logs in, a homepage with admin menus will appear. Admin menus include "insert traffic ticket data", "change user and traffic ticket data", "browse all data", and "change admin data". The "Add Data" menu is used to add traffic ticket data and user data. Add Traffic Ticket Data Form is used to add traffic ticket data. The "Add Data Form" is shown in Figure 5.

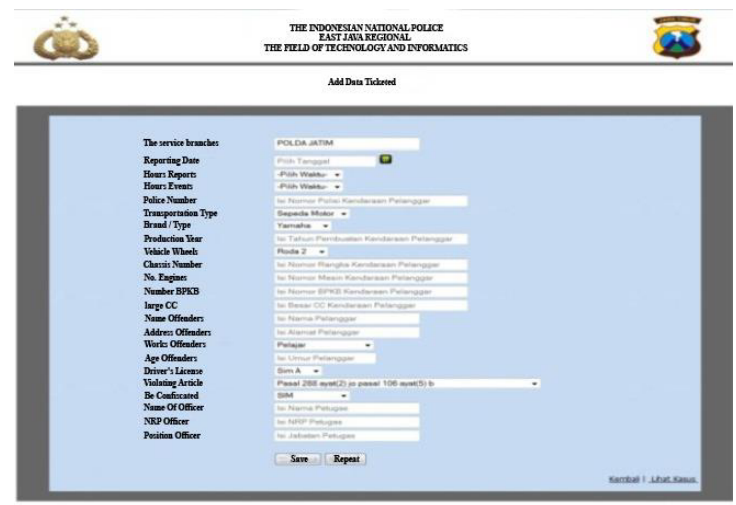

Figure-5. Add Traffic Ticket Data Form
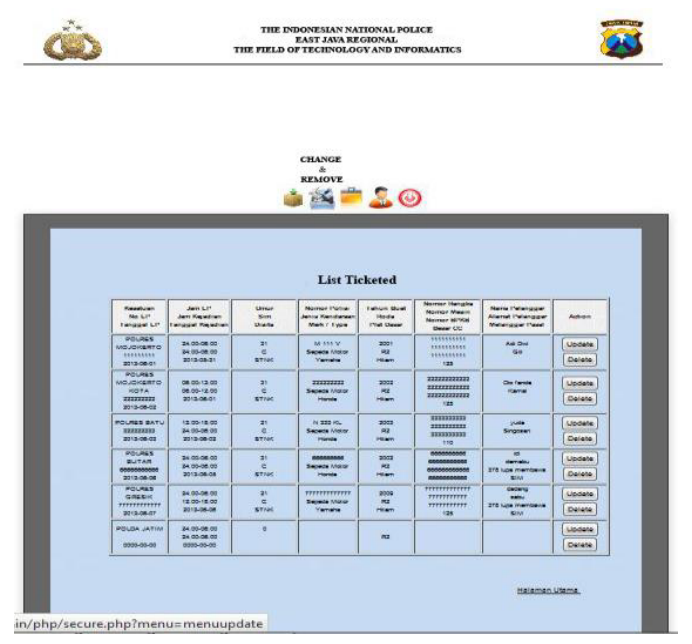

Figure-6. Page "Change Traffic Ticket Data"

Menus "Change Data" and "Delete Data". The page "Change Data" is shown in Figure 6. Menu 
"Change Account" of Polres is used to view and change profile data of Polres. Menu "All Data" is used to view all traffic ticket data, a summary of traffic ticket data by wheels, a summary of traffic ticket data by time, and a graph per Polres. Page "All Traffic Ticket Data" is used to view all traffic ticket data. Appearance of the traffic ticket data is shown in Figure 7.

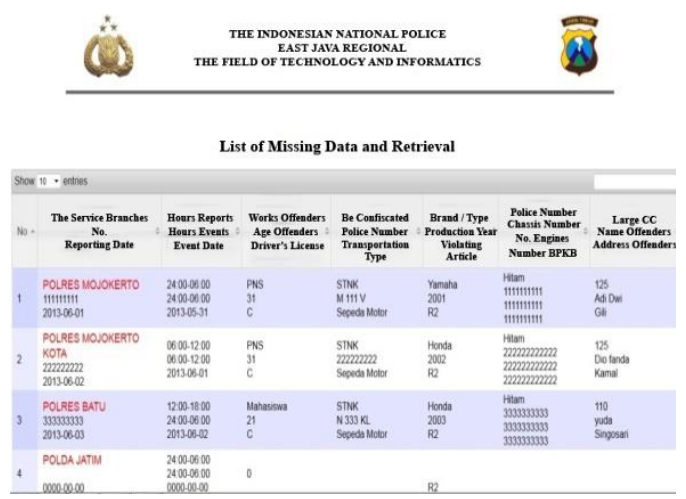

Figure-7. Page "All Traffic Ticket Data"
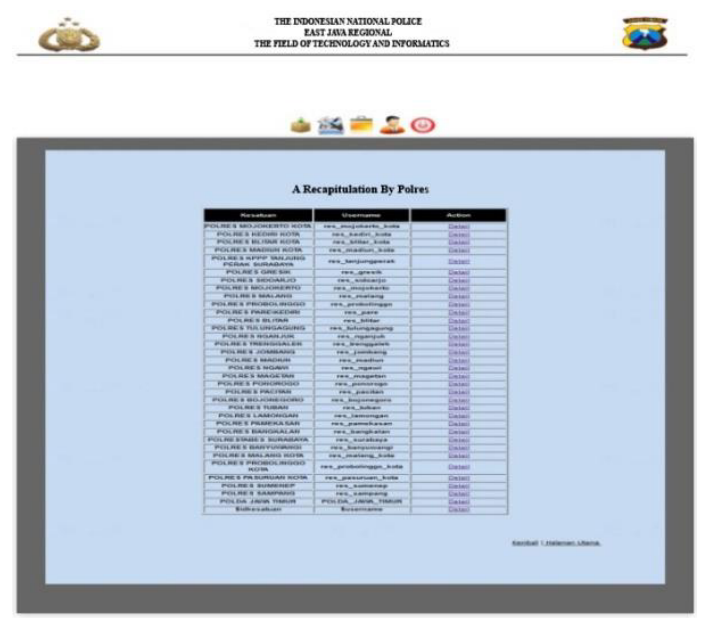

Figure-8. Page "View Data per Polres"
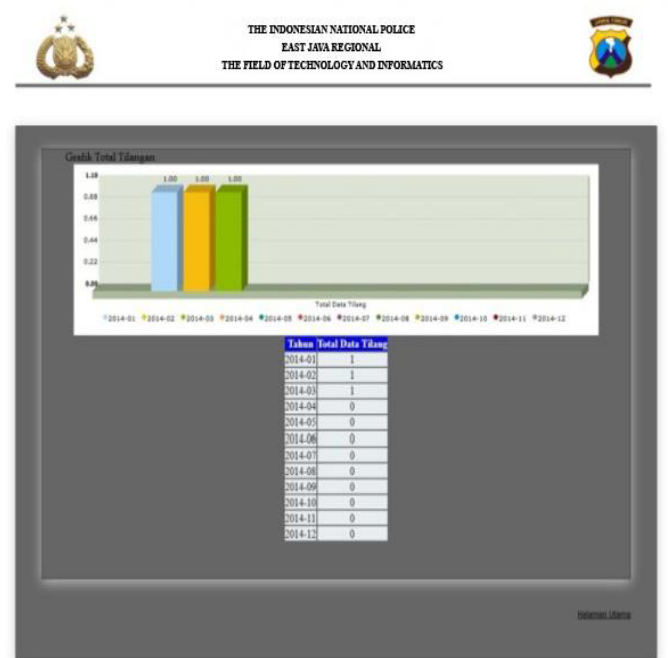

Figure-9. "Graph of Case Data per Polres"

Menu "Data per Polres" is used to view the summary of data per Polres. Menu "Summary of Data by Wheels" is used to view the summary of data by wheels per month. Menu "Summary of Data by Time" is used to view the summary of data by time or hours per month. Appearance of traffic ticket data is shown in Figure 8. Page "Graph of per User or Polres" is used to view the chart of data per Polres. "Graph of Case Data per Polres" is used to view the chart of case data per Polres. "Graph of All Case Data in Polda Jatim" is used to view the chart of all case data in East Java Police. The pages of the charts of data can be seen in Figure 9 and Figure 10.

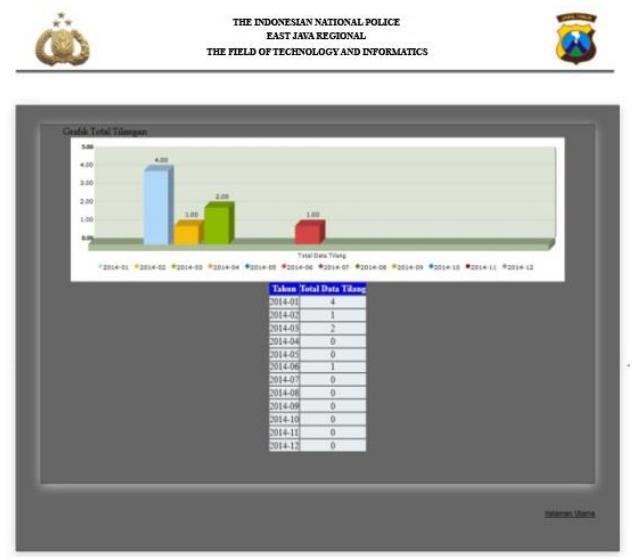

Figure-10. "Graph of All Case Data"

\section{Traffic Ticket Data Processing Information Systems}

Based on the study, the East Java Police have been implementing a Traffic Ticket Data Processing Information Systems, which could support managerial tasks and policy making. Availability and support of technological infrastructure, such as hardware, software, or network, to speeds up access to traffic ticket data processing Information Systems has not been adequate. An information system is a conceptual system and will run properly if the components, such as software, hardware, brain ware and network, functions properly to provide the correct decisions for its users (Kumar P.M., 2014).

Results of the study showed that the application of Traffic Ticket Data Processing Information Systems in each division has been being supported by software and hardware. Data and information between units/divisions have not been integrated since the intranet has not connected, which had negative impacts on the bureaucracy with regard to supplying the necessary data in a timely manner. Utilization of information technology within an information system provide an accelerated access and timeliness as well as the reduction of bureaucracy since it is capable of fast information generation with high accuracy (Iivari J., 2007), which has a positive impact on decision making.

In today's rapid technological developments, information systems support to a network constitutes a necessity to speed up acquisition of accurate and timely information fast. Information systems supported by an intranet network will have an impact on the high rate of data communication and provide advantages in a variety of transactions from a variety of different places that can cut the cost of the preparation and delivery of reports due to capability of online acquisition. Results showed that among the constraints 
and problems in the application of the traffic ticket data Processing Information Systems, in addition to the technological aspect, was the lack of understanding and awareness of human resources. More specifically, the assigned officers did not carry out their functions, duties and responsibilities properly at the operational level resulting in incomplete data needed for policy making.

Understanding and awareness of the functions and benefits of the information system will determine the quality of information produced by a system since the computer system has taken over human works in data processing; however, man has an important role as a user (Au N., and Cheng, T.C.E., 2012). (Al-Debei M.M., 2013) argue that the success of an information system is influenced by the perceived information quality and the perceived quality system which is a significant predictor for user satisfaction, while user satisfaction is also a significant predictor for the intended use and perceived individual impact.

Other components that play an important role in the handling and management of an information system are leadership and management. East Java Police's organizational structure consists of units or divisions with a considerable distance from Polres to another, requiring the structuring of the management information system to provide information for the benefit of the management for policy making. Presence of standard operating procedures and a clear organizational structure within each unit/division are needed to create a good collaborative relationship, which would in turn be able to create and maintain information systems useful and appropriate for decision making.

Results of the review of reports of Traffic Ticket Data Processing Information System showed that data inputting, data processing, data transformation and information (outputs) generation have not run as expected. The Format of Traffic Ticket Data Processing Information Systems has not been completed in full, as well as delivery of reports by each Polres was not on time, which adversely affected the quality of the information produced by the Traffic Ticket Data Processing Information Systems for management decision and policy making.

Quality information is measured by the accuracy of the information generated in the sense that it should be free from errors and not mislead those who receive it, as well as on time since delayed information would no longer useful and relevant information has benefits for recipients so that it can be useful for making a decision quickly and accurately in solving a problem (Choi Sue Young, et. al., 2010). Sophistication factor is no less important since a decision is a conscious and systematic effort to overcome the unfavorable situation in problem solving. Time orientation of a decision relates to expired information that will not support the decision-making process quickly and accurately.

Poor quality of information generated by a Traffic Ticket Data Processing Information Systems is inseparable from the handling and management of information systems, since the outputs of this system is information useful to stakeholders and decision makers in the East Java Police. Information systems that do not produce output but always receive input would put the input into a deep hole (Hevner A., and Chatterjee S., (2010).

Results also indicated that user's satisfaction with the Traffic Ticket Data Processing Information Systems was not significant. Satisfaction with the use of information technology can be measured from the aspect of behavior since behavior is one of the important aspects that relate directly to the user. Furthermore, interaction between user and computer devices is heavily influenced by perception, attitudes and affections inherent in human beings as users (Cheung C. M., and Lee M. K., 2008).

(Grispos G., et. al 2014) suggest that user behavior and a personal system are needed in the system development. This relates to the understanding and perspective of the system user since the perception of the personnel involved in the implementation of the system will take effect at the end of a system, whether the system is successful or not, acceptable or not, useful or not, if implemented. Furthermore, (Gil D.N., 2009) argues that the use of information technology by an individual, group, or organization is an important variable in the information system since its acceptance or rejection should be confirmed beforehand.

(Marchewka J.T., \& Kostiwa K., 2014) define usefulness as a level in which an individual believes that the use of a particular subject will be able to improve his or her performance. Results of the present study also showed that information generated by the Traffic Ticket Data Processing Information Systems for management policy-making in the East Java Police has not been optimally utilized since there were still many obstacles and shortcomings in the implementation stage, leading to inability to support management policy making. A new information system has operational significance in the life of an organization if the system supports the decision-making process, which means that an information system must be capable of supporting resolution of problems faced by users of the system (Al-Mamary Y.H., et. al., 2013).

Management Information System constitute a tool to manage processes which provides information for managers to support operations (Al-Mamary Y.H., et. al., 2014). Additionally, management information system is also a formal method that provides accurate and timely information to management to facilitate decision making and to make the organization capable of performing the functions of planning, operating and controlling effectively (Peffers K., et. al., 2007).

\section{CONCLUSION}

Application of the Web-based Traffic Ticket Data Information System has not been running as expected due to: (a) with regard to the relationship between the technological aspects and the human aspect as user, the implementation of Web-based traffic ticket data information has not yet provided ease of use. The level of use of the Web-based traffic ticket data information system has not been maximized; (b) with regard to the relationship between the human 
aspect as user and the organizational aspects, the awareness and understanding of police officers were still low. The assigned officers did not carry out their tasks properly, resulting in sub-optimal implementation of the web-based traffic ticket data information system; (c) with regard to the relationship between the organizational aspects and technological aspects, the cooperation between units/divisions in terms of exchange of information has not been well-established due to the lack of a clear standard operating procedures.

Information generated by the Web-based Traffic Ticket Data Information System has not yet had the significant level of quality in terms of accuracy, completeness or timeliness of information. As end users, the public were not yet satisfied with the information generated by the implementation of the web-based traffic ticket data information system. The information systems generated could not function as an information management system since in the implementation stage there were still many obstacles and shortcomings, leading to inability of the information generated for use to support management decision and policy and making.

\section{ACKNOLWEDGEMENT}

We would like to thank all those who have helped this study, particularly the East Java Police Chief and the personnel directly related to the results of the study.

\section{Reference}

Al-Debei M.M., (2013). Developing and Implementing a Web Portal Success Model. Jordan Journal of Business Administration, 9(1), 161-190.

Al-Mamary Y.H., Shamsuddin A., \& Aziati N., (2013). The Impact of Management Information Systems adoption in Managerial Decision Making : A Review, The International Scientific Journal of Management Information Systems, , 8, (4), 010-017.

Au N., \& Cheng, T. C. E. (2012). The formation of employee satisfaction with airline information systems. Journal of Travel \& Tourism Marketing, 29(4), 335-351.

Al-Mamary Y.H., Shamsuddin A., \& Aziati N., (2014). The Role of Different Types of Information Systems in Business Organizations: A Review, International Journal of Research, 1 (7), 333-339.

Cheung C. M., \& Lee M. K., (2008). The structure of Web-based information systems satisfaction: Testing of competing models. Journal of the American Society for Information Science and Technology, 59(10), 1617-1630.

Choi Sue Young, Heeseok Lee, and Youngjin Yoo., (2010) "The Impact of Information Technology and Transactive Memory Systems on Knowledge Sharing, Application, and Team Performance: A Field Study." MIS quarterly 34.4: 855-870.
Davis M.E., \& Phillips J.A., (2007). Learning PHP \& MySQL: Step-by-Step Guide to Creating Database-Driven Web Sites. O'Reilly Media, Inc.

Gil D.N., (2009). Management Information Systems And Strategic Performance: The Role Of Top Team Composition, International Journal of Information Management, 29(2), 104-110.

Grispos G., Glisson W.B., Pardue J.H., and Dickson M., (2014). Identifying User Behavior from Residual Data in Cloud-based Synchronized Apps. Conference on Information Systems Applied Research (CONISAR 2014), 6-9 November 2014, Baltimore Maryland, USA.

Hevner A., \& Chatterjee S., (2010). Design research in information systems: theory and practice (Vol. 22). Springer Science \& Business Media.

Iivari J., (2007). A paradigmatic analysis of information systems as a design science. Scandinavian Journal of Information Systems, 19(2), 5.

Kumar P.M., (2014). Information Technology: Roles, Advantages and Disadvantages. International Journal of Advanced Research in Computer Science and Software Engineering, 4, (6), 98-109.

Marchewka J.T., \& Kostiwa K., (2014). An application of the UTAUT model for understanding student perceptions using course management software. Communications of the IIMA, 7(2), 10.

Peffers K., Tuunanen T., Rothenberger, M.A., \& Chatterjee, S. (2007). A design science research methodology for information systems research. Journal of management information systems, 24(3), 45-77.

Ullman L.E., (2003). PHP and MySQL for dynamic web sites. Peachpit Press.

Valade J. (2007). PHP and MySQL for Dummies. John Wiley \& Sons.

Williams H.E., \& Lane D., (2004). Web database applications with PHP and MySQL. O'Reilly Media, Inc.

Zajaczek J.E.W., Götz F., Kupka T., Behrends M., Haubitz B., Donnerstag F., \& Becker H., (2006). eLearning in education and advanced training in neuroradiology: introduction of a web-based teaching and learning application. Neuroradiology, 48(9), 640-646. 